\title{
Crisis Planning: Increasing Effectiveness, Decreasing Discomfort
}

Michelle G. Hough, (Email: mgh11@psu.edu), Pennsylvania State University, McKeesport Campus John E. Spillan, (Email: jes40@psu.edu), Pennsylvania State University, DuBois Campus

\begin{abstract}
Although the percentage of businesses involved in crisis planning increased after September 11, 2001 , it is still alarmingly low. Some managers believe crisis planning unnecessary, while others become overwhelmed when attempting to plan for all potential crises. Even those managers who develop plans may find them overly-simplistic or ineffective when crises occur. This work discusses the importance of crisis planning and presents a five-step process to simplify planning efforts while increasing their effectiveness. Effective crisis preparedness can be achieved by forming a crisis team, analyzing vulnerabilities, creating strategies, working the plans, and assessing plan performance.
\end{abstract}

\section{INTRODUCTION}

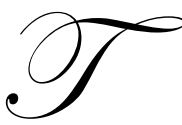

he old saying goes, into each life some rain must fall. Likewise, we might say, into each business some crisis must occur. Whether loss of data from a computer glitch, loss of equipment, or life due to a full-scale natural disaster, adversity strikes businesses with alarming frequency and little warning. Just as individuals save for rainy days to mitigate their ill-effects, businesses can benefit from employing a proactive strategy toward potential crises. Crisis management entails minimizing the impact of an unexpected event in the life of an organization (Spillan \& Hough, 2003). Oxford Executive Research Centre study showed that publicly traded companies able to execute disaster recovery plans reduced the initial negative capital impact by $60 \%$; companies unable to execute plans had initial losses equating to $11 \%$ of their capitalization and average stock price losses of almost $15 \%$ (West, 2003). In fact, evidence shows that the effective execution of well-developed crisis plans can not only control crises; it can create competitive advantage for the "afflicted" organizations.

In the pre-September 11 world, organizations traditionally did little to formally plan for adversity. Spillan and Hough's study of small businesses in New York and Pennsylvania showed that only 15\% of businesses surveyed had crisis management teams, that respondents demonstrated little concern for crises, and that concern was generated for a potential crisis only if the business had experienced that event previously (2003). Henry's pre-September 11 survey of Fortune 500 companies found that only 30\% of respondent organizations had crisis management plans (Henry, 2000). Overwhelmingly, businesses justified their apathy toward crisis management with reasons such as the improbability of crises occurring, the lack of need for planning due to the cohesiveness of the management team, and the use of insurance coverage as an acceptable crisis planning substitute (Caponigro, 2000, Mitroff, 1989).

Yet it appears that the tragic events of September 11, 2001, aided perhaps by recent corporate ethic scandals, have impacted organization's attitudes toward crisis management. Since the September 11 attacks, the American Management Association has surveyed members and customers regarding crisis management efforts and has found increasing attentiveness toward the discipline. In 2003, 64\% of respondents indicated they had crisis management plans, up from $49 \%$ in 2002 . Further, $62 \%$ of respondents have crisis management teams, up from 54\% in 2002, and $42 \%$ indicated they conduct crisis drills or simulations, up from $39 \%$ in 2002 (AMA, 2003). The approach to crisis management, whether reactive or proactive, has consequences that each manager has to weigh in relation to his/her business goals. The following illustration provides a graphic depiction of the crisis event stream for managers engaging in reactive and proactive decision making. 
Figure 1 - Crisis Management - Two Stances

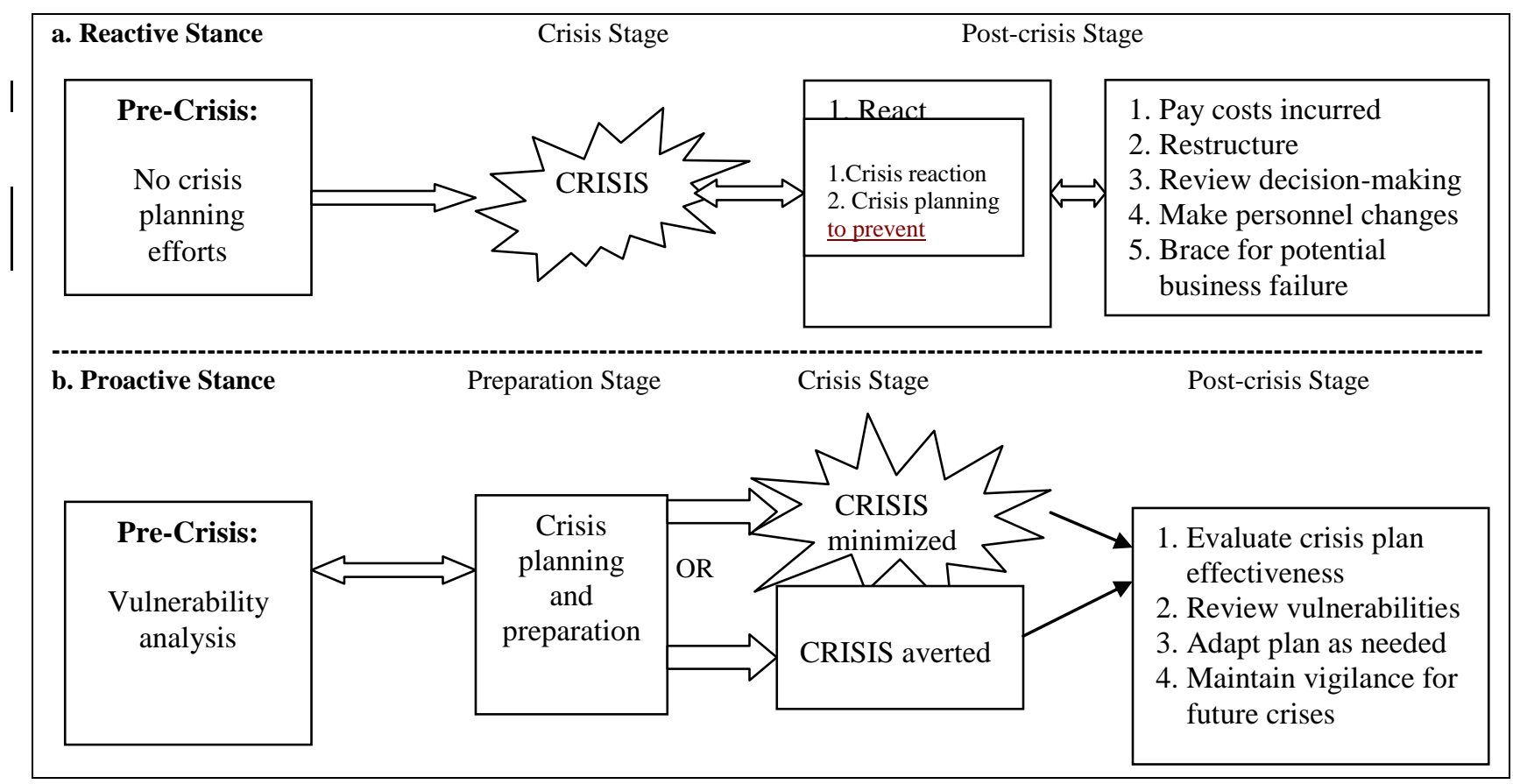

(Source : J. E. Spillan, Ph.D., M. G. Hough, D.Sc.)

Figure 1 illustrates the events which occur in crisis situations. In the reactive stance, decisions about the crisis are made after the event has occurred. In the proactive stance, managers have anticipated crises and have completed vulnerability analyses toward developing plans to deal with potential crises. The consequences of each management decision are significant. Managers must weigh the difference between the investments in planning for a crisis against the losses they may incur from failing to plan. Clearly, implementing some sort of crisis planning process provides significant benefit for the continued viability of the business.

\section{CRISIS PLANNING}

Traditionally, the field of crisis management has addressed the actions taken by an organization when confronted by a crisis. Caponigro (2000) defines crisis management as the function that works to minimize the impact of a crisis and help the organization gain control of the situation, while Whitman and Mattord (2003) define crisis management as the actions taken during and after a disaster. While proper management of an existing crisis is important, actively planning to prevent crises and to mitigate the effects of those crises which cannot be prevented is critical. To date, little attention has been given to this key component of crisis management. Crisis planning can be defined as proactively assessing and addressing vulnerabilities to avoid or minimize the impact of crises. It focuses on the activities that should be addressed before a crisis ever looms.

\section{CRISIS PLANNING PROCESS}

As a necessity, businesses are viewing crisis planning with increased interest. But understanding the importance of crisis planning is different from developing effective plans, particularly when management may have to sell the need for crisis planning to organizational cultures that previously looked upon the effort as a waste of time and money. Attempting to plan for all the potential crises that could conceivably strike a business can be time-consuming, tiresome, and difficult. As such, even organizations that choose to plan for crises may find their plans shallow, overly-simplistic, or ineffective when crises occur and plans are put to the test. To effectively tackle adversity then, management must not only believe in the value of crisis planning, they need to understand the components of effective 
crisis planning and implement those components in their organizations. Discussed here is a five-step process that management can follow to create sufficiently detailed, comprehensive crisis plans. By following the process of forming a team, analyzing vulnerabilities, creating strategies, working the plans, and assessing performance, managers can decrease their discomfort regarding crisis planning and increase the probability that their organizations will survive, or perhaps even benefit from, times of crisis.

\section{Step 1: Form A Crisis Team}

Look beyond the financial statements of any successful business and you will likely see a cohesive, effective management team. Just as the formation of an effective management team is critical to the financial success of an organization, the choice of the individuals who will comprise the crisis team is critical not only to successfully managing crises; it may be a decision upon which corporate survival rests. Gerber and Feldman (2002) suggest that the crisis team be comprised of the firm's top managers, including a senior accounting or financial officer, a senior human resources representative, a senior manufacturing or operations representative, a senior information systems or technology officer, a senior insurance or risk management representative, internal and external public relations/media relations representatives, and internal and external legal counsel.

Although designating the top management team as the crisis team undoubtedly will assure that crisis planning is viewed in a strategic manner, some adjustments to the team mix may be necessary to ensure its effectiveness. If certain top managers are relatively new to the organization, it may be beneficial to substitute a lowerlevel manager with greater organizational experience. Likewise, external consultants may be used to fill gaps of expertise regarding some crisis events with which the organization is not familiar. Additionally, the organization should investigate the possibility of retaining as consultants retired employees whose wealth of specific organizational knowledge may enrich the subsequent steps of analyzing vulnerabilities and creating strategy.

Further, regardless of education or experience, some individuals do not perform well in crisis situations. As such, it is critical that the team be formed of personalities whom not only work well as a team, but whom can operate in a pressure-filled environment, even for extended periods of time when necessary. Finally, consideration should be given to appropriate team size. Initially, it may seem desirable to compile a team with representation in every organizational area and with expertise in a wide variety of crisis situations, but problems of coordination and control increase proportionally with team size. Creating a very large crisis team conceivably could lead to less effective performance during a crisis event. For these reasons, effective team configuration may be the most critical step to ensuring comprehensive management of crises.

\section{Step 2: Analyze Vulnerabilities}

For some, critically assessing all the crises that potentially could strike a business is not only disheartening, it can be completely overwhelming. Most managers can easily list the three or four crises they most likely face - fire; floods; extended power outages; hurricanes or other natural disasters. Few, excluding those managers in organizations with risk management departments, can comprehensively list and rank all potential vulnerabilities. Additionally, the attacks on September 11, 2001 generated a new set of concerns formerly thought so improbable as to prompt immediate exclusion from consideration. In fact, the events of September 11 created an entirely new meaning to the phrase "worst case scenario" and may possibly be the primary impetus to increased management attention on crisis planning (Spillan \& Hough).

Table 1, revised from Crandall et al. (1999) to include terrorist activities, provides a detailed list of crises and impacts from which the crisis team can begin their vulnerability analysis. Depending upon the organization, additional crises may require assessment. For example, transnational corporations with operations in countries less than politically or economically stable may need to place more emphasis than their domestic counterparts on assessing vulnerabilities related to revolution, invasion, kidnapping of key managers, or governmental corruption. After tailoring the list of potential crises, the crisis team should analyze the events not only for probability of occurrence, but also to assess the associated financial, operational, human resource, and public relation consequences. Ideally, the 
outcome of vulnerability analysis will be a prioritized list of potential crises with some grouping of events which will require similar management strategies.

Table 1 - Crisis Classification Framework

\begin{tabular}{|c|c|c|}
\hline Category & Impact & Crisis Events \\
\hline Operational & $\begin{array}{l}\text { Short-term or long-term disruption of } \\
\text { organization's daily activities }\end{array}$ & $\begin{array}{l}\text { Loss of records permanently due to fire } \\
\text { Computer system breakdown } \\
\text { Loss of records permanently due to computer } \\
\text { system breakdown } \\
\text { Computer system invaded by hacker } \\
\text { Major industrial accident } \\
\text { Major product/service malfunction } \\
\text { Death of key executive } \\
\text { Breakdown of a major piece of production/service } \\
\text { equipment }\end{array}$ \\
\hline Public Image & Negative public perception & $\begin{array}{l}\text { Boycott by consumers or the public } \\
\text { Product sabotage } \\
\text { Negative media coverage }\end{array}$ \\
\hline Fraud & $\begin{array}{l}\text { Loss of stakeholder confidence, reduced employee } \\
\text { morale and productivity }\end{array}$ & $\begin{array}{l}\text { Theft or disappearance of records } \\
\text { Embezzlement by employee(s) } \\
\text { Corruption by management } \\
\text { Corporate espionage } \\
\text { Theft of company property } \\
\text { Employee violence in the workplace } \\
\text { Asset misappropriation }\end{array}$ \\
\hline Natural Disaster & $\begin{array}{l}\text { Temporary or permanent disruption of daily } \\
\text { activities, destruction of facilities or equipment, } \\
\text { loss of life }\end{array}$ & $\begin{array}{l}\text { Flood } \\
\text { Tornado } \\
\text { Hurricane } \\
\text { Earthquake }\end{array}$ \\
\hline Legal & $\begin{array}{l}\text { Negative public perception, loss of stakeholder } \\
\text { confidence, bankruptcy due to cost of legal } \\
\text { representation or payment of fines and penalties }\end{array}$ & $\begin{array}{l}\text { Consumer lawsuits } \\
\text { Employee lawsuit } \\
\text { Government investigation } \\
\text { Product recall }\end{array}$ \\
\hline Terrorism & $\begin{array}{l}\text { Temporary or permanent disruption of daily } \\
\text { activities, long-term consequences in employee } \\
\text { morale and confidence, destruction of resources, } \\
\text { loss of life }\end{array}$ & $\begin{array}{l}\text { Bomb } \\
\text { Kidnapping } \\
\text { Massacre } \\
\text { Chemical or biological attack }\end{array}$ \\
\hline
\end{tabular}

Adapted from Crandall, et al. (1999).

\section{Step 3: Create Strategies}

Armed with a prioritized list of potential crises, the crisis team can set to work on developing comprehensive strategies to avoid or mitigate crisis events. As with any strategic initiative, the role of the crisis team is not to create and orchestrate minutely detailed plans; its focus instead is to establish major goals and expectations for crisis survival along with sufficiently detailed directives to be implemented at functional levels. For example, it is probably counterproductive for a crisis team to create detailed disaster recovery plans in the event of a major computer system outage. Instead, the crisis team should focus on goals and objectives for recovery such as identifying the maximum acceptable loss of data, mandating a frequency for system backups, detailing expectations regarding the timeframe for system recovery, prioritizing the mission-critical systems for restart, and providing direction regarding the use of external disaster recovery installations. The systems operations group then would derive and implement the detailed disaster recovery procedures to accomplish the crisis team's goals and objectives. 
Relieved of attempting to plan to minute levels of detail, the crisis team adds the greatest value by focusing on the comprehensiveness of the strategies they deliver. A truly comprehensive strategy will focus on all aspects of the organization's survival including detailing interdependencies among departments; building contingencies in the task environment with customers, distributors, suppliers, and even some friendly competitors; and addressing requirements of the general environment such as liaising with employees' families, aid providers such as fire departments and emergency medical technicians, government agencies, affected local communities, and other stakeholders. Inherent in comprehensive strategy formulation is the development and utilization of effective, fail-safe mechanisms for communication, including the appointment of a corporate spokesperson that can interact with all parties in a knowledgeable, professional manner.

Finally, no crisis planning strategy is complete unless it includes a mechanism for attempting to circumvent crises from the outset. Given sufficient warning, most crises can be significantly diminished if not entirely avoided (Spillan \& Hough, 2003). The organization will benefit greatly if the crisis team mandates the development of an early warning system, complete with a list of indicator events which automatically trigger the execution of crisis plans. Employee preparedness is critical to the effectiveness of an early warning system. Employees who have received sufficient training, been exposed to comprehensive simulations and drills, and who have participated in the testing and fine-tuning of crisis plans will not only be vigilant in watching for early warning signs, they will likely be effective and efficient in executing the developed strategies and increasing the likelihood of a successful crisis outcome.

\section{Step 4: Work The Plans}

In theory, the preparation entailed in forming an effective crisis team, creating comprehensive crisis planning strategies, implementing the strategies in sufficient detail at functional levels, and training and preparing employees to perform effectively and efficiently in crisis situations should ensure that any crisis can be mitigated or avoided. In reality, few plans account for all potential variation or complexity in a given situation. Only rarely does a plan so perfectly fit the situation for which it was intended that no modifications are necessary and execution is flawless. Instead, organizations dealing with crises frequently are faced with the need to deviate from their plans in order to deal with unforeseeable complexities in the crisis situation.

In these instances, the wisdom and experience of both the crisis team and the effected employees is invaluable. To whatever extent is reasonable, the organization should work the plan but be sufficiently empowered and flexible to adapt to variations as events require. When adaptations are warranted, the crisis team should ensure that the deviations are documented, including the rationale and the outcome of the changes, so that the changes can be evaluated after the crisis has passed and incorporated as needed into future plans. As important as creating and rehearsing plans for crises are, understanding when and how to deviate from the plans may be even more crucial to surviving a crisis situation.

\section{Step 5: Assess Performance}

Sometimes, even the best-laid plans fail despite all efforts to the contrary. Whether the execution of a crisis plan was a dismal failure or an astounding success, lessons can be learned from analyzing actual performance against the expectations of the plan. If performance fell short, it is important to question why and determine how to remedy the shortcomings in the future. If performance exceeded all expectations, possibly turning a potential disaster into an advantageous situation, analyzing the success can provide important insights that may be transferred to other situations. Innovations developed during crisis situations may even be applied to normal operating conditions to create a long-term strategic advantage. Regardless of the outcome, analysis of past performance almost always provides significant lessons for the future.

\section{CONCLUSION}

Since September 11, 2001, managers are increasingly aware of the importance of crisis management. While managing an existing crisis is important, actively planning to prevent crises is critical. Crisis planning, or proactively 
assessing and addressing vulnerabilities to avoid or minimize the impact of crises, focuses on the activities that should be addressed before a crisis ever looms. Planning for crises can minimize their impact and even create competitive advantage yet trying to anticipate all the adverse events that might occur in an organization and then plan related crisis strategies can be disheartening or overwhelming. By following the steps of forming a team, analyzing vulnerabilities, creating strategies, working the plans, and assessing performance, managers can decrease their discomfort regarding crisis planning and increase the probability that their organizations will survive and possibly benefit from times of crisis.

\section{REFERENCES}

1. American Management Association, 2003 AMA Survey: Crisis Management and Security Issues.

Online: http://www.amanet.org/research/index.htm.

2. Brown, B. “The Disaster Business," Management Today, October 1993, pp. 42-48.

3. Caponigro, J. The Crisis Counselor: A Step-by-Step Guide to Managing a Business Crisis (Chicago: Contemporary Books, 2000).

4. Crandall, W. \& Menefee, M. "Crisis Management in the Midst of Labor Strife: Preparing for the Worst," SAM Advancement Management, 61, 10(1993): 1, 11-15.

5. Darling, J. "Crisis Management in International Business: Keys to Effective Decision-making," Leadership \& Organization Development Journal, 15, 8(1994): 3-8.

6. Dean, J. "Disaster and Recovery," Government Executive, 33, 15(December 2001): 63-66.

7. Fink, S. Crisis management: Planning for the inevitable (Lincoln, NE: Guild Backinprint.com, 2000).

8. Gerber, J. \& Feldman, E. "Is Your Business Prepared for the Worst?" Journal of Accountancy, April 2002, pp. 61-64.

9. Henry, R. You'd Better Have a Hose if You Want to Put Out the Fire (California: Gollywobbler Productions, 2000).

10. Hickman, J. \& Crandall, W. "Before Disaster Hits: A Multifaceted Approach to Crisis Management," Business Horizons, March-April 1997, pp. 75-79.

11. Jones, G. \& George, J. Contemporary Management, 3rd ed. (New York: McGraw-Hill, 2003).

12. Meyer, G. \& Holusha, J. When It Hits the Fan: Managing the Nine Crises of Business (Boston: Houghton Mifflin, 1986).

13. Mitroff, I. (1989) "Programming for Crisis Control”, Security Management, (October 1989): 75-79.

14. Muller, R. "Corporate Crisis Management”, Long Range Planning, 18, 5(1985): 38-48.

15. Spillan, J. \& Hough, M. "Crisis Planning in Small Businesses: Importance, Impetus and Indifference," European Management Journal, 21, 3(2003): 398-407.

16. West, M. "Crisis Management's Real-time Frontier: Using New Technology to Secure Critical Data," Public Relations Strategist, 9, 3 (Summer 2003): 30-31.

17. Whitman, M. \& Mattord, H. Principles of Information Security. (Massachusetts: Course Technology, 2003).

18. Wilderoter, D. "Crisis Management: A New Plan Is Necessary," National Underwriter (Property/Casualty/Employee Benefits), 91(33): 34-35 \& 40-41. 